
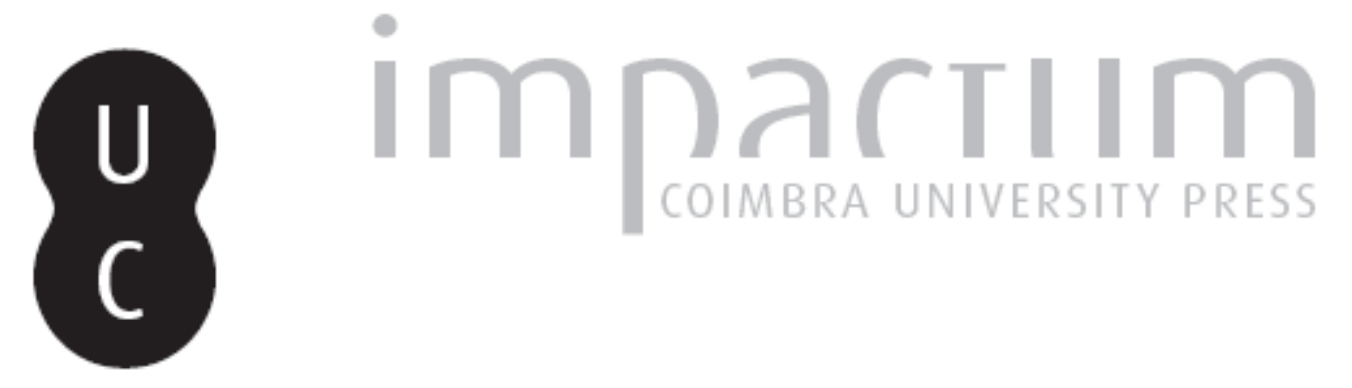

\title{
Fornos de ânforas do Monte do Bugio: notícia preliminar
}

\author{
Autor(es): Diogo, António . Dias
}

Publicado por: Imprensa da Universidade de Coimbra

URL persistente:

URl:http://hdl.handle.net/10316.2/45723

DOI:

DOI:https://dx.doi.org/10.14195/1647-8657_19_3

Accessed : $\quad$ 26-Apr-2023 11:29:17

A navegação consulta e descarregamento dos títulos inseridos nas Bibliotecas Digitais UC Digitalis, UC Pombalina e UC Impactum, pressupõem a aceitação plena e sem reservas dos Termos e Condições de Uso destas Bibliotecas Digitais, disponíveis em https://digitalis.uc.pt/pt-pt/termos.

Conforme exposto nos referidos Termos e Condições de Uso, o descarregamento de títulos de acesso restrito requer uma licença válida de autorização devendo o utilizador aceder ao(s) documento(s) a partir de um endereço de IP da instituição detentora da supramencionada licença.

Ao utilizador é apenas permitido o descarregamento para uso pessoal, pelo que o emprego do(s) título(s) descarregado(s) para outro fim, designadamente comercial, carece de autorização do respetivo autor ou editor da obra.

Na medida em que todas as obras da UC Digitalis se encontram protegidas pelo Código do Direito de Autor e Direitos Conexos e demais legislação aplicável, toda a cópia, parcial ou total, deste documento, nos casos em que é legalmente admitida, deverá conter ou fazer-se acompanhar por este aviso.

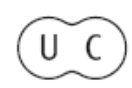


FACULDADE DE LETRAS

INSTITUTO DE ARQUEOLOGIA

CONIMBRIGA

VOLUME XIX

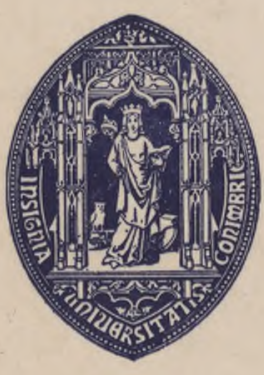

UNIVERSIDADE DE COIMBRA

1980 
António M. Dias Diogo

Professor do Ensino Básico

FORNOS DE ÂNFORAS DO MONTE DO BUGIO. NOTÍCIA PRELIMINAR

Conimbriga, XIX, 1980, 147-150

RESUMo : O autor dá breve notícia de três fornos que terão produzido ânforas de tipo Dressel 14/ Beltrán IV. Acham-se parcialmente destruídos e não foram ainda objecto de escavação.

RÉSUMÉ: Trois fours dans la vallée du Sado ont été partiellement détruits.

D'après l'auteur, qui n'en a pas pu faire la fouille, ils ont produit des amphores de type Dressel 14/ Beltrán IV. 
(Página deixada propositadamente em branco) 


\section{FORNOS DE ÂNFORAS DO MONTE DO BUGIO NOTÍCIA PRELIMINAR}

De entre as prospecções que fiz, entre 1976 e 1979, na zona de «riba-Sado», avulta o elevado número de fornos que referenciei e destaca-se a datação do oleiro «D.M.T.», produtor de ânforas do tipo Dressel 14 e situado na herdade principal da Companhia Agrícola da Barrosinha $\left({ }^{\mathrm{x}}\right)$.

Era minha intenção ter já publicado todos os resultados das prospecções num trabalho monográfico. Dificuldades diversas levaram-me a abandonar parcialmente esse projecto e a fazê-lo anteceder de várias notícias preliminares, de modo a divulgar material inédito de alguma importância.

Os fornos do Bugio eram prioritários: muitos investigadores estão empenhados no estudo da produção de ânforas desta zona e o seu contacto directo com o forno que aqui precariamente descrevo, tornou-se impossível já que ele foi destruído.

Denunciados por uma extensão de cerca de $150 \mathrm{~m}$ virtualmente cobertos de cacos, os fornos do Monte do Bugio estão situados ao quilómetros 75,5 do caminho de ferro do Vale do Sado (coordenadas hectométricas: $158.7 \mathrm{~N}, \quad 164.4 \mathrm{E}$ na Carta Militar 1:25.000, folha n. $\left.{ }^{\circ} 476\right)$.

São, actualmente, em número de dois e foram muito maltratados pela construção do caminho de ferro e, posteriormente, pela vala de rega. Segundo informação do Sr. Agostinho Brígido,

0) Datável de Cláudio. Estava associado a sigillata sudgálica, nomeadamente a uma forma Dragendorff 27 marcada M.IV(lius) SEV(erus).

Conimbriga, 19 (1980), 147-150 
que trabalhou na referida vala de rega, haveria um outro forno de que não restam vestígios.

Do primeiro forno pouco se vê, destruído e escondido como está por terra e silvas. O segundo, $50 \mathrm{~m}$ mais a norte, é circular e feito de «lateres» vulgares. Apresentava à data da minha primeira visita, uma pequena sequência de parede circular a que se encontravam adoçados os alicerces de três dos arcos que sustentavam a grelha. (Medida da corda do arco de círculo formado pela parede: $210 \mathrm{~cm}$; altura visível da parede: $155 \mathrm{~cm}$. Alicerce central: polígono irregular com a altura actual visível de $85 \mathrm{~cm}$, largura de $47 \mathrm{~cm}$ e profundidade de $44 \mathrm{~cm}$. Está separado do pilar sul por um intervalo de $18 \mathrm{~cm}$ e do norte por um intervalo de $25 \mathrm{~cm}$ ).

Os fragmentos que ilustram esta breve notícia correspondem a ânforas do tipo Dressel 14/Beltrán IV. São um bordo de lábio ligeiramente perolado (na parte superior do bordo é observável uma saliência, de aspecto esponjoso, provocada por defeito de feitura); uma asa, de secção irregularmente oval com uma canelura vertical exterior; o último fragmento desenhado é um bico fundeiro terminando em botão. Todos estes fragmentos foram recolhidos dos restos da fornalha do segundo forno. A pasta, que está muito calcinada, e é de cor ocre nos fragmentos menos atingidos pelo fogo, apresenta grande quantidade de grãos de quartzo que atingem facilmente os 1 e $2 \mathrm{~mm}$; é porosa, com muitas fendas e bolhas de ar.

António M. Dias Diogo 

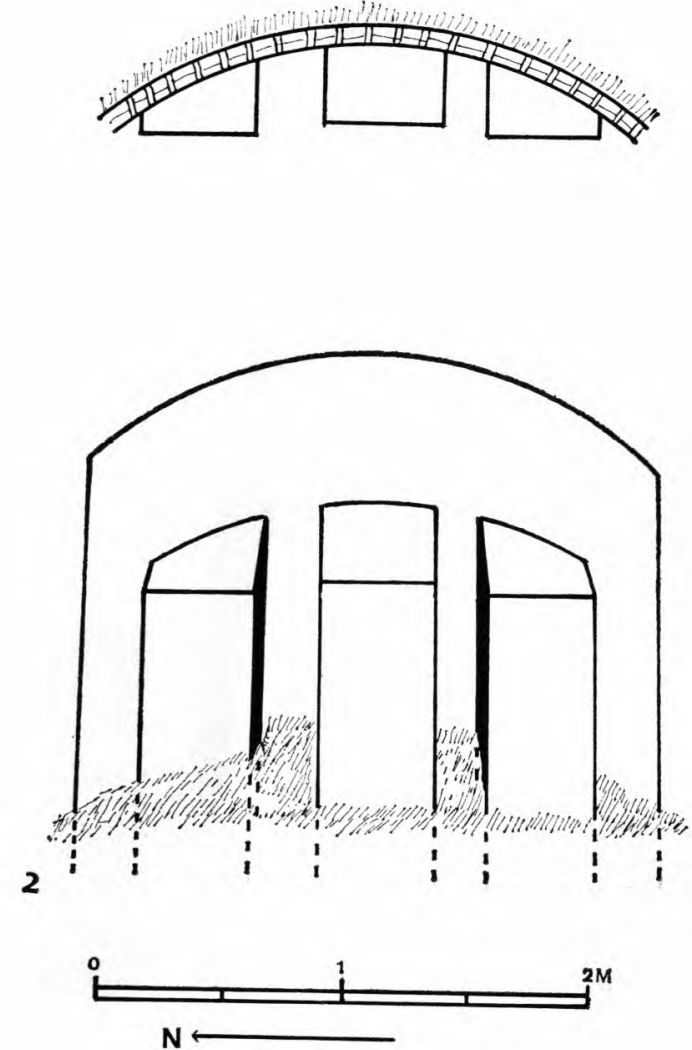

1 - Planta do segundo forno

2 - Alçado do segundo forno 


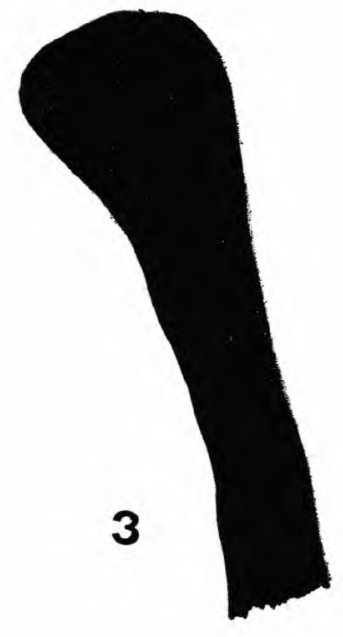

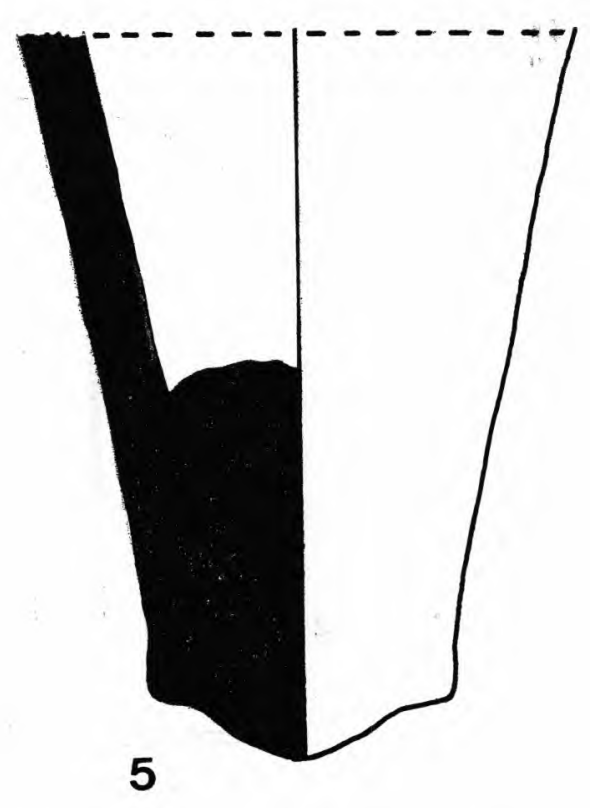

4

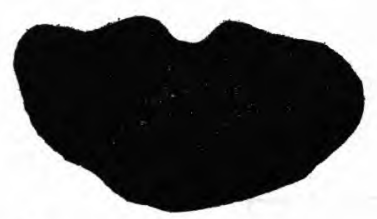

3-5 - Bordo, asa e bico fundeiro recolhidos na fornalha do segundo forno 


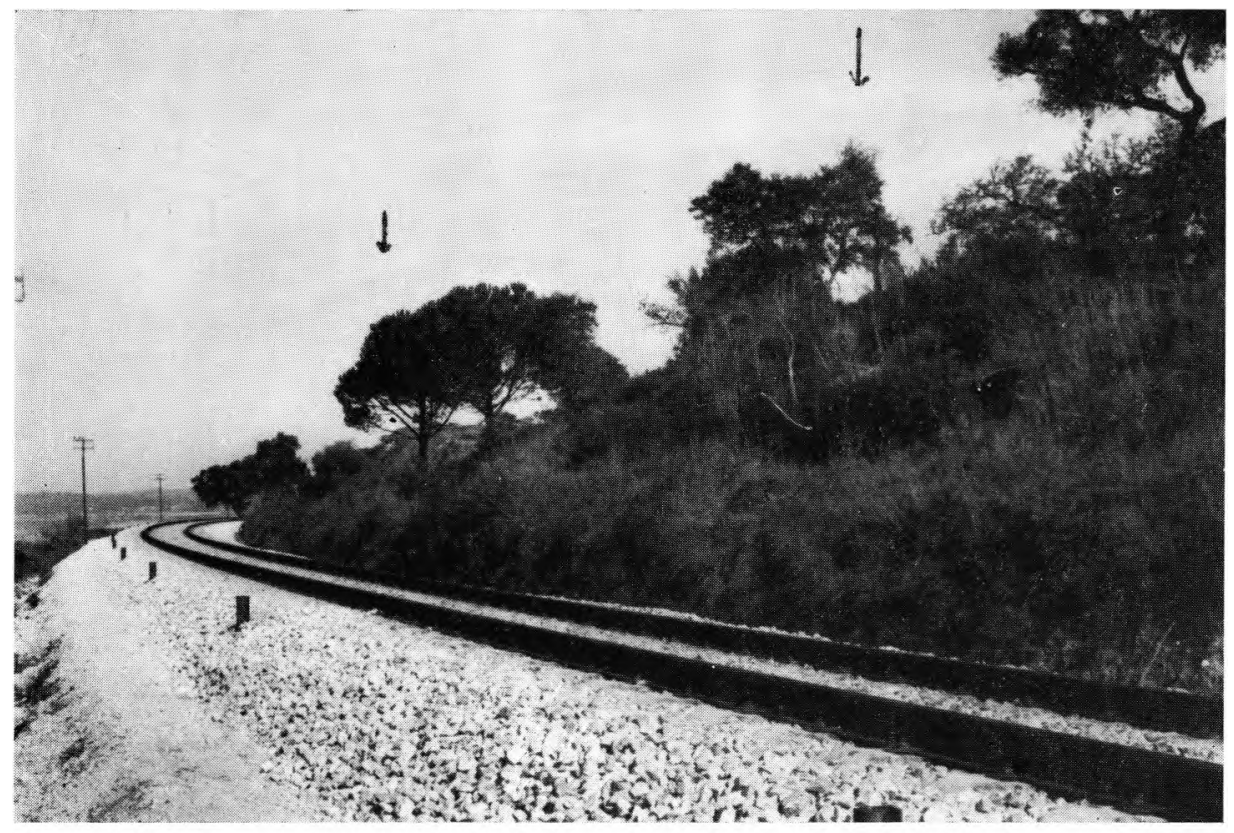

Situação dos fornos 